\title{
Cartaphilus
}

Revista de investigación y crítica estética

\section{DIALÉCTICA DEL SPLEEN EN CHARLES BAUDELAIRE}

\section{DIALECTICS OF THE SPLEEN IN CHARLES BAUDELAIRE}

\section{IRENE LEÓN TRIBALDOS}

UNIVERSITAT DE VALÈNCIA

Resumen: A partir del texto Sobre algunos motivos en Baudelaire de Walter Benjamin y la propia obra del poeta Charles Baudelaire, pretendemos mostrar dos lecturas de sus escritos para exponer tanto el encuentro entre ambas interpretaciones, que tiene lugar en su obra mediante el spleen, como la Vieldeutigkeit de Theodor W. Adorno de estos mismos. Este término, que se ha traducido por "multivocidad", aparece en la obra Prismas (Adorno, 1962) expresando la posibilidad de múltiples interpretaciones de una realidad. De esta forma, estudiaremos el dinamismo entre lo que hemos Ilamado "la hendidura del spleen" y "la huida del spleen", dos momentos de la obra baudelairiana que consiguen objetivar en sus poemas la realidad histórica que vivió este autor. Trataremos de descifrar, asimismo, si el spleen que tanto pesó al poeta queda, o puede quedar redimido, mediante su literatura.

Palabras clave: spleen, Baudelaire, hendidura, huida, Vieldeutigkeit.

\begin{abstract}
From the text On some motifs in Baudelaire by Walter Benjamin and the work of the poet Charles Baudelaire, we intend to show two readings of his writings in order to expose the encounter between both interpretations, which takes place in his work throuth the spleen, and the Vieldeutigkeit of Theodor W. Adorno of these. This term, which has been translated by "multivocity", appears in the work Prismas (Adorno, 1962) expressing the possibility of multiple interpretations of a reality. In this way, we will study the dynamism between what we have called "the cleft of the spleen" and "the escape of the spleen", two moments of Baudelaire's work that manage to objectify in his poems the historical reality that this autor lived. We will also try to decipher if the spleen that weighed the poet so much is redeemed, or can be redeemed, through his literature.
\end{abstract}

Key words: spleen, Baudelaire, cleft, escape, Vieldeutigkeit. 


\section{INTRODUCCIÓN}

Il faut être toujours ivre. Tout est là: c'est l'unique question. Pour ne pas sentir l'horrible fardeau du Temps qui brise vos épaules et vous penche vers la terre, il faut vous enivrer sans trêve. Mais de quoi? De vin, de poésie ou de vertu, à votre guise. Mais enivrez-vous (Baudelaire, 1935). ${ }^{1}$

Tedio, hastío, melancolía. Charles Baudelaire vivió en el París del siglo XIX arrastrando el spleen sobre el que tanto escribiría y que da título a varios de sus textos. Considerado como el padre de los poetas malditos, su obra tendrá una fuerte influencia en toda la literatura (y parte de la filosofía) posterior.

Han sido numerosas las interpretaciones que se han hecho de los textos de Baudelaire, tratando de comprender tanto su obra como al propio poeta a través de ella. En el presente trabajo, sin embargo, no trataremos de hacer sino una lectura de sus escritos y del momento histórico que estos objetivan (en términos hegelianos). Nos proponemos dibujar la insalvable contradicción en la obra de Baudelaire desde una dialéctica negativa (precisamente porque los textos baudelairianos resultan, en sí mismos, una carencia de síntesis reconciliadora) y defender una salida del paradigma estético que busque cualquier intento de comprender racionalmente a Baudelaire o de encontrar el sentido en sus obras.

\section{HENDIDURA DEL SPLEEN}

Escribe María Zambrano que Baudelaire es el padre de todos los poetas modernos (Zambrano, 2006), y esto se hace patente en Sobre algunos motivos en Baudelaire. Walter Benjamin trata de exponer en este texto cómo Baudelaire logra objetivar el mundo en sus obras, en tanto que plasmar en estas el momento histórico en el que dichas obras surgen, desde el nuevo modo de hacer experiencia que Freud denomina shock.

El shock freudiano no es sino una experiencia traumática que no pasa por los filtros de la racionalidad, lo que se traduce en la introducción del inconsciente a la hora de hacer experiencia de la realidad. Este modo de hacer experiencia conlleva que aquellos estímulos que percibamos mediante el shock se almacenarán sin atender a los sesgos que proyectaríamos desde la racionalidad en ellos,

\footnotetext{
${ }^{1}$ XXXIII: “Hay que estar siempre borracho. Todo consiste en eso: es la única cuestión. Para no sentir la carga horrible del Tiempo, que os rompe los hombros y os inclina hacia el suelo, tenéis que embriagaros sin tregua. | Pero ¿de qué? De vino, de poesía o de virtud, de lo que queráis. Pero embriagaos".
} 
puesto que no pasan por la consciencia. Benjamin compara esto con la "memoria involuntaria" de la que hablaba Proust, que sería "lo que no ha sido 'vivenciado' con conciencia y explícitamente, es decir, aquello que al sujeto no le sucedió como 'vivencia'" (Benjamin, 2008a).

Esta puntualización realizada por negación determinada es muy importante, porque Benjamin está haciendo referencia directa a la concepción de la estética que plantea Dilthey en su Poética:

La creación del poeta se basa siempre en la energía de las vivencias. En su organización, que tiene gran resonancia en los tonos vitales, la noticia muerta de un diario en la sección policial, el escueto informe de un cronista o la leyenda grotesca se torna vivencia (Dilthey, 2000).

Al rechazar esto, y priorizar las experiencias que pertenecen "al género de las sorpresas" y que "atestiguan de este modo una insuficiencia en el hombre" ${ }^{2}$-comenta Benjamin citando a Valéry, quien ya expuso su salida del paradigma epistemológico que Dilthey defendía-, estamos rechazando también la tradición hermenéutica que seguirán autores como Gadamer o Maclntyre. Esta línea de pensamiento defiende la necesidad de buscar el sentido en las obras para que podamos comprender racionalmente lo que en ellas está tratando de decir el autor.

Entonces, si el poeta de la modernidad es aquel capaz de hacer experiencia mediante el shock, está saliendo de las vivencias interiorizadas racionalmente. $Y$ con este salto estamos anunciando una poesía que no habrá que leer buscando un sentido, porque es producida desde una experiencia irracional que se objetiva en la propia obra.

Benjamin rechaza la idea del sentido tanto en la obra de arte concreta como en la historia. Al desechar una concepción "con sentido" de la historia, reniega también de la visión lineal-que implica un progreso- que solemos tener de la misma. Al separarse de esta concepción que podríamos llamar teleológica de la historia, la noción de "progreso" cae por su propio peso: si la historia no es lineal ni hay un sentido último tras la misma, no podemos progresar hacia ningún fin. Además, este filósofo sostiene también que todo "progreso" implica que algo ha de arruinarse, y así lo expone en la novena tesis de su obra Tesis de filosofía de la historia (Benjamin, 2008b), donde introduce la figura del "ángel de la historia" ${ }^{3}$.

\footnotetext{
${ }^{2}$ Paul Valéry, Analecta, París, 1935, p. 264 (cita del propio Benjamin).

3 “Ha vuelto el rostro hacia el pasado. Donde a nosotros se nos manifiesta una cadena de datos, él ve una catástrofe única que amontona incansablemente ruina sobre ruina, arrojándolas a sus pies. Bien quisiera él detenerse, despertar a los muertos y recomponer lo despedazado. Pero desde el paraíso sopla un huracán que se ha enredado en sus alas y que es tan
} 
El ángel de la historia de Walter Benjamin es una alegoría que trata de denunciar que la historia ("una cadena de datos") es solo un constructo que "amontona incansablemente ruina sobre ruina". El hombre, sin embargo, se niega a ver esto porque la idea de "progreso" que le ha sido inculcada (una suerte de avance racional y tecnológico) le hace mirar únicamente hacia el futuro. El ángel, por su parte, que "ha vuelto el rostro hacia el pasado", es el único capaz de ver la destrucción que ha dejado la historia -"una catástrofe única"- a su paso.

No obstante, Benjamin ha encontrado la obra de un hombre que fue capaz de objetivar en su producción artística los inicios de este pensamiento, característico de la modernidad y la crítica al mismo, casi un "ángel de la historia" hecho poeta: Charles Baudelaire.

"Baudelaire se conforma con homenajear lo inmemorial, que a él se le ha hurtado, en la figura de lo pasado de moda", escribe Benjamin a partir de un par de versos del poema "Recueillement" (Baudelaire, 2018). Sin embargo, este no es el único lugar donde Baudelaire se retrotrae a tiempos pretéritos; en un fragmento titulado "Le crépuscule du soir" (Baudelaire, 1935) escribe: "comme sous le noir présent transperce le délicieux passé" ${ }^{4}$. Porque Baudelaire detecta que el presente histórico en el que él se encuentra está suponiendo un punto de noretorno. Sin embargo, como comentamos al principio, esta experiencia de la modernidad que hace Baudelaire es inconsciente, comienza con el shock.

Hemos abandonado, entonces, a la figura del poeta diltheyano, que se sentaba para reflexionar calmada y racionalmente los estímulos que recibía, y de los cuales nacían posteriormente las vivencias desde las que crearía su poema. Baudelaire no puede sentarse: es un ávido paseante que recorre durante horas las calles de París. No puede reflexionar con calma: sabemos que poseía numerosos "tics" nerviosos. $\mathrm{Y}$, desde luego, no hace experiencia racional del mundo: hace experiencia desde el shock:

Lecteur paisible et bucolique,

Sobre et naïf homme de bien,

Jette ce libre saturnien,

Orgiaque et mélancolique (Baudelaire, 2018). ${ }^{5}$

fuerte que el ángel ya no puede cerrarlas. Este huracán le empuja irreteniblemente hacia el futuro, al cual da la espalda, mientras que los montones de ruinas crecen ante él hasta el cielo. Ese huracán es lo que nosotros llamamos progreso".

4 “[C]omo bajo el negro presente se trasluce el delicioso pasado".

5 "Epígrafe para un libro condenado": "Lector, tú tan bucólico y sereno, | hombre de bien, morigerado y cándido, | no aceptes este libro saturnino | que huele a melancólico y a orgiástico". 
Al igual que en el poema "Al lector" con el que Benjamin comienza su texto, en "Épigraphe pour un libre condamné" se hace patente que "[e]l lector al que se orientaba Baudelaire lo suministra la posteridad" (Benjamin 2008a); esto es, que el lector al que se dirigía Baudelaire aún no existía. El lector bucólico contra el que arremete desde la ironía en este fragmento es el que se mantiene todavía en el paradigma de las vivencias, el que aún no se ha dado cuenta de que el beatus ille ha perdido todo el sentido entre las masas que entran uniformadas a las fábricas cada mañana a trabajar.

Y del mismo modo que se han perdido estos poetas y lectores arquetípicos, ha perdido el aura. Benjamin ve el aura como una "capacidad de ese alzar la mirada" (ib.), que está, sin embargo, llegando a su decadencia. Ya no tiene lugar "la aparición irrepetible de una lejanía" (íd.), que no es sino la facultad de reacción, de devolver la mirada, con que este pensador habla de la obra de arte enfática. Y la obra de arte ya no puede devolver la mirada porque los ojos de los sujetos que las contemplan "han perdido la capacidad de mirar" (ib.). Esa es la experiencia de la modernidad que Baudelaire objetiva desde el shock-que le produce esta misma situación- en su obra. La modernidad ha arrasado con todo el paradigma teórico anterior, pero el capitalismo que surge en ella está acabando con el aura del arte. Las oleadas multitudinarias de seres indistinguibles entre sí, que han perdido toda característica particular en pro del aumento de la masa, ya no saben mirar:

Mais les ténèbres sont elles-mêmes des toiles

Où vivent, jaillissant de mon oeil par milliers,

Des êtres disparus aux regards familiers (Baudelaire, 2018). ${ }^{6}$

Y lo que queda a Baudelaire tras esa pérdida del aura a la que conduce el momento histórico en el que él se encuentra no es otra cosa que el spleen.

Como escribe Benjamin, "Baudelaire arremete contra la multitud en su conjunto, y lo hace empleando la ira impotente de quien arremete contra la lluvia o el viento" (Benjamin, 2008a), y esa ira frustrada, que no puede devenir sino en hastío, en spleen, es la que objetivará en su obra (de nuevo, inconscientemente).

\footnotetext{
6 "Pero las tinieblas son ellas mismas lienzos | donde viven, brotando de mi ojo por miles, | seres desaparecidos con miradas familiares" (hemos optado por traducir este fragmento por nuestra cuenta porque en la versión en castellano con la que contamos se perdía el matiz que en francés original recalca la importancia de la mirada).
} 


\section{HUIDA DEL SPLEEN}

Et de longs corbillards, sans tambours ni musique,

Défilent lentement dans mon âme; l’Espoir, Vaincu, pleure, et l'Angoisse atroce, despotique,

Sur mon crâne incliné plante son drapeau noir.

(Baudelaire, 2018)

El spleen es hastío, tedio, melancolía. Algunos autores han hablado de "aburrimiento", pero esto apenas roza la superficie. Esa "Angustia atroz y despótica", que no puede haber sido objetivada en la obra sino mediante la experiencia del shock jamás podría ser "aburrida". Y la experiencia del spleen que se hace mundo a través de la obra de Baudelaire solo puede ser provocada en -y por- la modernidad. Benjamin escribe que la ira - de la que hablábamos al final del apartado anterior- "mide con sus estallidos el fatal compás de los segundos del que es siempre víctima el melancólico" (Benjamin, 2008a). Esa ira, esos estallidos violentos, es lo que Benjamin ve en la obra de Baudelaire como expresión de contraste entre los antiguos poetas divinizados y el poeta hastiado y "shockeado" de la modernidad.

Así surge el spleen, el hastío ante los cambios que París está sufriendo, ante las ruinas que quedan del progreso arrollador. Esta es la angustia asfixiante que encontramos en la obra de Baudelaire:

Horreur! Je me souviens! Je me souviens! Oui! Ce taudis, ce séjour de l'éternel ennui, est bien le mien. Voici les meubles sots, poudreux, écornes; la cheminée sans flamme et sans braise, souillée de crachats; les tristes fenêtres où la pluie a tracé des sillons dans la poussière; les manuscrits, raturés ou incomplets; l'almanach où le crayón a marqué les dates sinistres! (Baudelaire, 1935) ${ }^{8}$

El polvo, huella visible del paso del tiempo, envuelve la "morada del Eterno hastío" en que Baudelaire se ve a sí mismo obligado a vivir; siempre me-

\footnotetext{
7 "Spleen": "Veo largos entierros, sin tambores ni música, | que desfilan por mi alma, lentamente; vencida, | la Esperanza solloza, y la Angustia, despótica, | clava sobre mi cráneo una negra bandera".

8 “iHorror! ¡Ya recuerdo! ¡Ya recuerdo! ¡Sí! Este desván, esta morada del Eterno hastío, es la mía. ¡Estos son los muebles necios, polvorientos, descantillados; la chimenea sin llama y sin ascua, mancillada por los escupitajos; las tristes ventanas llenas de polvo en que trazó surcos la lluvia; los manuscritos llenos de tachones, sin concluir; el calendario en que el lápiz marcó las fechas siniestras!".
} 
lancólico, siempre angustiado. ¿No hay forma de redención, acaso?

Sí, vomitando. Devolviendo esa angustia al lugar en que se generó: haciéndola mundo a través de la obra de arte. Entonces, ¿es el arte una sangría espiritual para encaminarnos hacia la Sorge ${ }^{9}$ heideggeriana? Nuestra respuesta aquí es contundente: el arte no existe con la finalidad de curar a nadie. No podemos sobrecargar al arte obligándolo a dibujarse en torno al cumplimiento de una función última. $\mathrm{Y}$, trayendo de nuevo a Benjamin, sin finalidad ulterior se pierde todo sentido.

Esta eterna búsqueda del sentido desde la que muchos autores han tratado de entender a Baudelaire mezclando sus textos y su vida, es lo que precisamente más ha atentado contra la obra del poeta. María Zambrano, lectora de Valéry, hace un acercamiento a Baudelaire en su obra Filosofía y poesía. En un pasaje, escribe:

Y en este camino de la poesía consciente, Paul Valéry significa un paso decisivo y quizá la identificación más total hasta ahora de pensamiento y poesía, desde el lado poético, en su culto a la lucidez. (...) [P]or primera vez, el poeta confiesa lo que durante siglos ha mantenido en silencio: el trabajo (Zambrano, 2006).

Es notable el esfuerzo de Zambrano por reflejar cómo la estética de Valéry hace patente que el modelo clásico de poeta que escribe sin derramar una sola gota de sudor ha caducado. Pero concluye -a nuestro modo de ver, erróneamente- que trabajo es sinónimo de lucidez y consciencia (no hace falta más que echar un vistazo al modelo de producción en cadena desde el que se trabaja en el capitalismo para darnos cuenta de que esta asociación no siempre es adecuada). Zambrano, en su búsqueda del eterno sentido, trata de defender que el trabajo dignifica al poeta (y da sentido a su vida). Así, caracteriza a Baudelaire como "soberbio y humilde, soberbio en quien vence la humildad, se define a sí mismo como pecador (...). Un pecador que espera salvarse como poeta" (ib.). Pero con esto lo único que estamos consiguiendo es hacer una lectura pseudopsicoanalítica de la obra de Baudelaire basándonos en su persona. No estamos bajando a escuchar al texto, solo lo estamos tomando como excusa para proyectar nuestras tesis, probablemente incluso previas a la lectura del mismo.

En esta línea, Sartre habla en su obra Baudelaire de un hombre frío, que ama los secretos, al que le gusta el orden y la racionalización, que se permite a sí mismo una serie de pecados detalladamente premeditados que ejecuta con una templanza imperturbable. Y sin embargo, comenta que al mismo tiempo sus poemas nos muestran a un hombre fetichista que tiene "muy serias razones para compadecer a quien no ama la muerte" (Sartre, 1968), un alma condenada por sus pecados, que a la vez se auto-redime en los mismos. Por muy literario que

\footnotetext{
9 Se suele traducir por "cura" o "cuidado". Heidegger defendió que la Sorge era necesaria para dar sentido a la existencia (tanto a la propia como a la de los otros).
} 
parezca este acercamiento a Baudelaire, al final no es sino una caracterización de su persona, una interpretación que imprime casi a puñetazos la teoría existencialista (Sartre no se olvida de hacer hincapié en la muerte) en sus resoluciones sobre el poeta y su obra.

Siguiendo la defensa del principio de literalidad que plantea Adorno en "Aufzeichnungen zu Kafka" (Adorno, 1962) ${ }^{10}$, consideramos que para tratar la obra de Baudelaire hemos de bajar desde la teoría a los textos, a la literalidad de sus poemas. Aquí no hay anécdotas de las rivalidades con su padrastro, ni comentarios sobre quién o quién no asistió a su entierro, ni mucho menos cualquier intento de trazar su personalidad a voluntad propia con escuadra y cartabón. Aquí hay una obra de arte concreta con unas palabras materiales que trataremos de descifrar, pero que ya no buscaremos comprender desde un paradigma racionalista que intente encontrar algún tipo de sentido trascendental.

La literalidad en la obra de Baudelaire es grotesca:

Aucuns t'appelleront une caricature,

Qui ne comprennent pas, amants ivres de chair,

L'élégance sans nom de l'humaine armature.

Tu réponds, grand squelette, à mon goût le plus cher! (Baudelaire, 2018) ${ }^{11}$

La literalidad en la obra de Baudelaire es angustiosa:

Sans cesse à mes côtés s'agite le Démon;

II nage autour de moi comme un air impalpable;

Je l'avale et le sens qui brûle mon poumon

Et l'emplit d'un désir éternel et coupable (ib.). ${ }^{12}$

La literalidad en la obra de Baudelaire es desesperanzada: “Qu'envers nous le Néant est traître" (ib.) ${ }^{13}$.

$\mathrm{Y}$ precisamente por todo esto consideramos, junto con Benjamin, que es-

${ }^{10}$ Este título se ha traducido por "Notas sobre Kafka”, aunque quizá debiera hablarse de "garabatos", puesto que "zeichnungen" significa "dibujos" en alemán.

11 "Siempre habrá quien te llame adefesio, los ebrios | de gozar toda carne, y que nunca comprenden | la elegancia sin nombre del humano armazón. ¡Oh, esqueleto, me agradas más que nada en el mundo!".

12 "A mi lado se agita sin cesar el Demonio, | flota en torno de mí como un aire impalpable; | le respiro y le siento abrasar mis pulmones | que me llena de un ansia sin final y culpable".

13 "Que hasta la Nada llega a traicionarnos". 
te poeta consigue como pocos otros objetivar la experiencia de la modernidad (que es grotesca, angustiosa y desesperanzada) en sus obras: "a la ineficacia del consuelo, al fracaso mismo del fervor y al malograrse de la misma obra se arrancaron poemas" (Benjamin, 2008a); a las experiencias del poeta les son arrancadas -violentamente- las palabras que conformarán los poemas.

Ese spleen del que hablábamos es, entonces, insalvable. Pero sí podemos alcanzar a evadirnos, al menos temporalmente, de la realidad que nos lo produce, opina Baudelaire. No hay forma de huir de la angustia, pero tenemos la posibilidad de silenciarla mediante el amor y los paraísos artificiales. La otra lectura de su obra parte así del spleen y recorre todos los "pecados" que el poeta comete para escapar del asfixiante hastío: "Tomad una porción grande [de hachís] como una nuez, llenad con ella una cucharita y poseeréis la felicidad, la felicidad absoluta con todas sus embriagueces, con todas sus locuras juveniles y también con sus infinitas beatitudes" (Baudelaire, 2014), dice con respecto a esta droga ${ }^{14}$. En cuanto al amor, cabría redactar otro trabajo que hablase solo de este en la obra de Baudelaire. Baste por ahora con citar: "Adorable sorcière, aimes-tu les damnés?" (Baudelaire, 2018) ${ }^{15}$.

Y es que lo que Baudelaire destaca no es el progreso naciente que podemos ver en las grandes ciudades, sino la otra cara de la modernidad, la decadente, la de los derrotados de la historia, diría Benjamin: "Le coeur content, je suis monté sur la montagne | D'où l'on peut contempler la ville en son ampleur, | Hôpital, lupanars, purgatorie, enfer, bagne" (Baudelaire, 1935) ${ }^{16}$.

\section{CONCLUSIÓN}

Baudelaire no es un filósofo (sí, un filósofo) al uso. En vez de partir de conceptos puros a priori, comienza desde un prostíbulo, fumando opio y bebiendo vino. Rechaza cualquier intento de dar sentido a ninguna expresión de la realidad porque, por si quedaba alguna duda, la modernidad que él experimenta acaba por poner la irracionalidad de la realidad ( $y$ nos vemos aquí obligados a salir de Hegel y su tesis de "Todo lo real es racional y todo lo racional es real") de manifiesto. Incluso rechaza una trascendencia de aquello que los poetas siempre han divinizado: la belleza y el amor.

Une nuit que j'étais près d'une affreuse Juive,

Comme au long d'un cadavre un cadavre étendu,

\footnotetext{
${ }^{14}$ Baudelaire se refiere a las drogas como "paraísos artificiales", de ahí el título de su obra homónima.

15 "Adorable hechicera, ¿amas al condenado?".

${ }^{16}$ Epílogo: “A la montaña he subido, satisfecho el corazón. | En su amplitud, desde allí, puede verse la ciudad: | un purgatorio, un infierno, burdel, hospital, prisión".
} 
Je me pris à songer près de ce corps vendu

A la triste beauté dont mon désir se prive (Baudelaire, 2018). ${ }^{17}$

Y es que, cuando rechaza esa especie de metafísica del amor trascendental, Baudelaire ve que el amor son solo dos cuerpos que se encuentran. Y esta experiencia, que no realiza de modo racional, sino que le impacta como el shock que es, es la que objetiva en la obra.

Hemos expuesto dos lecturas de la obra de Baudelaire que parten del gesto de descifrar (como diría Adorno) la literalidad del texto, observando qué realidad histórica es la que se ha hecho mundo a través de estas obras de arte concretas. $Y$ esto ha sido posible por la Vieldeutigkeit de estos textos, que permite ambas lecturas atendiéndonos al susodicho principio de literalidad, y que además es la causante de que hablemos de una dialéctica del spleen. Entendemos que no hay un dualismo entre estas interpretaciones ni "dos Baudelaires" distintos, sino una dialéctica en movimiento que rehúye la síntesis. Primero, porque eso implicaría concebir la obra de Baudelaire como una totalidad única con un sentido último; y segundo, porque la modernidad que aquí ha quedado objetivada no permite la síntesis reconciliadora. Es el propio spleen, sin embargo, el que marca el ritmo entre ambos momentos: la experiencia que hace Baudelaire de la modernidad le provoca la hendidura del spleen, del que trata de huir mediante el amor y los paraísos artificiales. Sin embargo, en esta salida al mundo exterior se ve forzado al reencuentro con la modernidad en la que vive, y así tiene lugar este movimiento dialéctico que queda objetivado -aunque de un modo inconsciente- en la obra de Charles Baudelaire.

\section{BIBLIOGRAFÍA}

ADORNO, T.W. (1962): Prismas: La crítica de la cultura y la sociedad. Traducción de Manuel Sacristán. Barcelona: Ariel, pp. 260-292.

BAUDELAIRE, C. (1863): El pintor de la vida moderna. Recuperado de: http://www.ecfrasis. org/wp-content/uploads/2014/06/CharlesBaudelaire-El-pintor-de-la-vida-moderna.pdf.

(1935): El spleen de París (Los pequeños poemas en prosa) Traducción de Enrique Díez Canedo. Recuperado de: http://www.cervantesvirtual.com/obra-visor/poemas-en-prosa-0/html/ff0099ba-82b1-11df-acc7-002185ce6064 1.html\#l 1.

\footnotetext{
17 “Cierta noche, abrazando a una horrible judía, I como junto a un cadáver un cadáver tendido, pensé al verme tan cerca de aquel cuerpo venal | en su triste belleza que ha acallado el deseo".
} 
(2014): Los paraísos artificiales. Recuperado de: https://www.guao.org/ sites/default/files/biblioteca/Paraisos\%20artificiales\%20.pdf.

(2018): Las flores del mal. Traducción de Carlos Pujol). Barcelona: Austral.

BENJAMIN, W. (2008a): Obras. Libro I, vol. 2. Edición de Holf Tiedemann \& Hermann Schweppenhäuser. Traducción de Alfredo Brotons Muñoz Madrid: Abada, pp. 207-259.

(2008b): Tesis sobre la historia y otros fragmentos. Traducción de Bolívar Echevarría. México: Ítaca.

DILTHEY, W. (2000): Poética. Traducción de Elsa Tabernig. Buenos Aires: Losada, pp. 53-109.

GADAMER, H.G. (1996): "Estética y hermenéutica”. Daimon, no 12, pp. 5-10. Traducción de José Francisco Zúñiga García

HEGEL, G.W.F. (1989): Lecciones sobre la estética. Traducción de Alfredo Brotóns Muñoz. Madrid: Akal.

SARTRE, J. P. (1968): Baudelaire. Traducción de Aurora Bernárdez. Buenos Aires: Losada.

VALÉRY, P. (1998): Teoría poética y estética. Traducción de Carmen Santos. Madrid: Visor, pp. 71-103.

ZAMBRANO, M. (2006): Filosofía y poesía. México, D.F.: Fondo de Cultura Económica. 